Article

\title{
Fostering Digital Participation for People with Intellectual Disabilities and Their Caregivers: Towards a Guideline for Designing Education Programs
}

\author{
Vanessa N. Heitplatz \\ Department of Rehabilitation Technology, TU Dortmund, 44227 Dortmund, Germany; \\ E-Mail: vanessa.heitplatz@tu-dortmund.de
}

Submitted: 25 October 2019 | Accepted: 26 February 2020 | Published: 14 May 2020

\begin{abstract}
In Germany, libraries or public training centers offer education programs for different target groups to foster digital participation. Yet, those programs often do not meet the requirements of people with intellectual disabilities, their formal caregivers or social institutions. A high degree of personal and organizational effort, lack of caregivers' knowledge and expenditure of time materialize as barriers for caregivers in social institutions to support their clients to achieve digital literacy. However, the desires of people with intellectual disabilities to improve their digital skills have risen steadily in the last years. This article addresses the question of how education programs should be designed to meet the needs of people with intellectual disabilities, their formal caregivers, and social institutions. Therefore, requirements were derived from a secondary analysis of 24 semi-structured interviews with formal caregivers in social organizations, focus groups containing 50 people with intellectual disabilities, and an additional interview study with five experts form research and practice. As a result, a guideline with ten main points for designing education programs for people with disabilities, caregivers and social institutions is presented in this article.
\end{abstract}

\section{Keywords}

formal caregivers; education programs; inclusive education; digital literacy; intellectual disability

\section{Issue}

This article is part of the issue “Digital Inclusion Across the Globe: What Is Being Done to Tackle Digital Inequities?" edited by Bianca C. Reisdorf (University of North Carolina at Charlotte, USA) and Colin Rhinesmith (Simmons University, USA).

(C) 2020 by the author; licensee Cogitatio (Lisbon, Portugal). This article is licensed under a Creative Commons Attribution 4.0 International License (CC BY).

\section{Introduction}

We live "in the age of the always-on and alwaysconnected citizen" (Keates, 2019, p. 101). Nowadays, former offline activities increasingly shifted into the online world: online-banking, information research or online-shopping are examples for that (e.g., Bühler \& Pelka, 2014). According to Pelka (2017), the process of digitalization encompasses not only technological but also social transformation processes which call for digital skills of both; people who depend on support and institutions that aim to promote the participation of these people. Those who are lacking access or competencies in self-determined internet usage have limited opportunities for participation in accessing knowledge and often have a lower socio-economic status and less social networks (e.g., Dobransky \& Hargittai, 2016;
Pelka, 2017; Shpigelman, 2018). The ability to understand and to use information from a variety of digital sources has become important in our digitalized society. This ability is called digital literacy and, according to Bawden (2008), comprises competencies like internet searching, hypertext navigation, knowledge assembly, and content evaluation (Bawden, 2008; Koltay, 2011). While the term digital literacy describes concrete competencies of a person, media literacy is an umbrella concept, which describes "the ability to access the media, to understand and to critically evaluate different aspects of the media and media content to create communications in a variety of contexts" (Koltay, 2011, p. 213). This article mainly refers to the term digital literacy, unless otherwise stated, as it is about learning, understanding, and using information from the Internet by people with disabilities. 
Chadwick, Wesson, and Fullwood (2013) found that especially older people and people with cognitive, physical, and sensory impairments have difficulties in using the Internet. Financial and economic barriers, lack of governmental, policy or organizational support as well as missing opportunities for training or education can restrict the participation of these groups of people and lead to digital divides (des Power, Power, \& Rehling, 2007). Thus, usage of digital media, especially through smartphone devices, is also steadily rising among people with disabilities:

Smartphones are very popular among them and fit perfectly their requirements. Even if they had not any previous experience with them before, learning how to use them would be advantageous, since these devices will become useful in some moment of their lives. (Gómez, Torrado, \& Montoro, 2017, p. 2)

Recent studies indicated that smartphones have opened up many opportunities. For people with hearing impairments the smartphone has become increasingly important because many apps and technical features exist that make everyday life easier for them (e.g., Ismaili \& Ibrahimi, 2017). Also, people with visual impairments benefit from numerous apps and assistive technologies, e.g., navigation systems for the smartphone, screen readers, and text-to-speech functions as technologies to assist online activities (e.g., Murata, 2019). Despite these developments in mobile computer technology, people with intellectual disabilities often seem to be excluded from digital opportunities. Chadwick et al. (2013, p. 379) found that people with intellectual disabilities are "least likely to gain access to and receive the full benefits from the Internet." Dobransky and Hargittai (2016) even mentioned a digital disability divide among disabled people. Lack of access, socio-economic barriers or influences by their social environment are reasons for such divides. The next section presents the state of research on Internet use and digital divides by and among people with intellectual disabilities.

\subsection{Research on Internet Usage of People with Intellectual Disabilities}

Nowadays, digital divides are researched on several levels. One of these divides exists regarding the Internet use and access by people with intellectual disabilities compared to the general population.

$75 \%$ of Germans are using a smartphone (Initiative D21, 2018, p. 20). In contrast, only $34 \%$ of people with intellectual disabilities use a smartphone. Access to and usage of (digital) media depends on age, living situation and the type of impairment (des Power et al., 2007; Dobransky \& Hargittai, 2016). Haage and Bosse (2017) found that among people with disabilities, people with intellectual disabilities are those with lowest smartphone utilization rates:
- $55 \%$ of people with hearing impairments;

- $46 \%$ of people with visual impairments;

- $45 \%$ of people with physical impairments;

- $34 \%$ of people with learning difficulties and intellectual disabilities report having access to a smartphone.

This is particularly astonishing considering that the smartphone, as a so-called smart product (Lee \& Shin, 2017), contains many technical functions and possibilities to facilitate access to the Internet for this group of people (e.g., read aloud function, text reader, autocomplete functions).

Ågren, Kjellberg, and Hemmingson (2019) revealed that Internet usage between young people with and without intellectual disabilities (aged between 13-20 years) differed in a significantly lower proportion in terms of "access to internet-enabled devices and performed activities...than the reference group." The authors noted, however, that some web applications are associated with a high degree of cognitive and linguistic skills that arise as barriers for people with intellectual disabilities. Dobransky and Hargittai (2016) came to similar conclusions. These authors found that people with disabilities use the Internet less often than people without disabilities. As reasons for this, the authors cited missing accessibility but also a lack of digital skills of people with intellectual disabilities. Gómez et al. (2017) analyzed smartphone usage of people with Down Syndrome and found a great interest and usage rate of those people using smartphone devices. The authors pointed out that people with Down Syndrome still lack digital literacy and need support in training their (digital) skills to learn how to use digital devices.

Besides, the social environment of people with intellectual disabilities (i.e., parents, friends, formal caregivers) takes a special role to provide one-to-one support for primary contact and the usage of technology (Chadwick, Quinn, \& Fullwood, 2017; Nälsund \& Gardelli, 2012). Heitplatz, Bühler, and Hastall (2019) also showed that opportunities for using and trying new technologies depend on the relationship between formal caregivers and individuals with intellectual disabilities. In line with these results, Hoppestad (2013) identified lack of knowledge or training as well as insufficient caregiver support as barriers. Ramsten, Marmstål Hammar, Martin, and Göransson (2017, p. 712) revealed "lack of organizational support and comprehensive strategies for the use of Information and Communication Technologies (ICT) in municipal social care for people with intellectual disability." The authors stated that "comprehensive vision and organizational support" are often lacking in those social contexts (Ramsten et al., 2017). These and other studies (e.g., Chiner, Gómez-Puerta, \& Cardona-Moltó, 2017; Löfgren-Mårtenson, Molin, \& Sorbring, 2018) found that the environment plays an important role in the use and access to technologies for people with intellectual disabilities. 
A widespread prejudice is that people with intellectual disabilities would be incompetent to learn how to use the Internet or new technologies because of their cognitive impairment (Corrigan \& Rao, 2012). In contrast, Nälsund and Gardelli (2012) showed that people with intellectual disabilities are able to improve their digital literacy through short interventions with ICT and the help of their caregivers. The authors also pointed out that the attitudes of caregivers towards competences of people with intellectual disabilities are often low (Nälsund \& Gardelli, 2012). Such prejudices are common against these group of people and can lead to restrictions of human rights and social discrimination (Chadwick et al., 2013). Li-Tsang, Yeung, Choi, Chan, and Lam (2007) trained persons with mild-to-severe deficits in basic computer skills such as using a mouse. After a 6-month follow-up, most participants in the study maintained "the ability to perform simple operations using the mouse or spacebar, yet could not complete operations involving multiple steps such as web browsing" (Li-Tsang et al., 2007, p. 13). However, the results of these studies indicated that people with intellectual disabilities are also able to learn how to use technology if they are given the opportunities and support to do so. Education with, via and through media is fundamental for belonging and participating in our mediatized society (e.g., Zorn, Schluchter, \& Bosse, 2019). To promote digital literacy, resources from all people who are involved in this process are required. This includes financial and time resources, cognitive skills or the recognition that digital training is important (e.g., Pelka, 2017). The ability to use digital devices, accessing the Internet and to perceive education programs is closely linked to the attitudes of the social environment and the organizational support provided by social institutions (e.g., Chadwick et al., 2017; Heitplatz et al., 2019; Ramsten et al., 2017).

\subsection{Aim and Research Question}

Although some of the presented studies have shown that ICT interventions with people with intellectual disabilities are important for enhancing digital literacy, there is little research on how exactly these interventions should be designed to meet the needs and requirements of social organizations, formal caregivers and people with intellectual disabilities. It is important that professionals understand the connection between inclusion and media education and possess necessary skills to integrate them into their daily work and pass them on to their clients (e.g., Zorn et al., 2019). Opportunities of enhancing digital literacy for people with disabilities are increasingly discussed in special education, media education, and communication sciences. Concerning people with disabilities, these are still new research fields in Germany (Bosse \& Pola, 2017). This article contributes to that field of research and aims to develop a guideline as an orientation for the implementation of education programs in social institutions. This guideline is intended to improve ed- ucation programs to enhance digital literacy for people with intellectual disabilities and their formal caregivers. This study also examines different stakeholder perspectives on how education programs for people with disabilities should be designed to improve digital participation opportunities. The research question is therefore: Which criteria are important for designing education programs to promote digital literacy for people with disabilities?

\section{Sample and Methods}

To answer the research question, the interview material of an already conducted study in $\mathbf{2 0 1 8}$ was analyzed secondarily. Furthermore, five additional interviews with experts from the research field were conducted. The following section describes the methodology and the sample of the study.

Initially, a qualitative study conducted in 2018 with 24 formal caregivers (13 males, 11 females, aged between 26 and 58) in social institutions in Germany (Heitplatz et al., 2019) was secondarily analyzed considering the research question of this study to find out about the views and perspectives of formal caregivers on the role of education programs to enhance digital literacy for people with intellectual disabilities.

During the same period of time, focus groups were conducted featuring people with intellectual disabilities in formal caregivers' institutions. A total number of 50 (23 males, 27 females, aged between 18 and 35) participants with intellectual disabilities took part in eleven focus groups. The focus groups aimed to find out what kind of digital media is used by people with intellectual disabilities, what problems they might face and what further wishes they might have (e.g., support, education). The procedure in evaluation and transcription, as well as the open coding process, are described in Heitplatz et al. (2019).

In the analysis of the interview transcripts, it became clear that even though there are comparatively few offers for people with disabilities in Germany, these do not seem to be known to the formal caregivers in the social institutions. To find out about this gap and to get a multidisciplinary perspective, five additional interviews were conducted in July and August 2019 in a second step with experts from the research field, namely: Dr. Bastian Pelka at the Social Research Centre Dortmund, Central Scientific Institute of TU Dortmund, and Head of the research area "Work and Education in Europe," who provided a scientific and political perspective; Dr. Nadja Zaynel, Head of the PIKSL Laboratory in Düsseldorf, a model for inclusive media education in Germany, and who provided the perspective of a communication scientist; Dr. Christoph Kaletka at the Social Research Centre Dortmund, Central Scientific Institute of TU Dortmund, also member of the management board and who accompanied the conception of the PIKSL laboratories; Junior Professor Ingo Bosse, Head of the Department of Physical-Motor Development at TU Dortmund, and who 
provided both practical experience and a scientific perspective to the interviews; and finally Christian Möser, from TMT Bildungsprojekte (Paderborn, Germany) who offered perspective and experience as a media-pedagogy and education consultant for new media.

The interview guideline for the experts contains questions about participants' perceived relevance of digital literacy for people with disabilities. The transcription and evaluation of these interviews followed the same procedure as the interviews of the focus groups and facility managers in Heitplatz et al. (2019).

\section{Results}

This section presents the results of the interviews with the formal caregivers, the experts and the people with intellectual disabilities. At the end of the section, the most important points are summarized. Section four discusses the results and presents the guideline. All quotations in this text have been translated from German into English.

\subsection{Opinions of Formal Caregivers on Media Education for People with Disabilities}

First, the results of the interviews with the formal caregivers will be presented. The topics that were most frequently mentioned by the caregivers are listed. These are suitability, mobility as well as lack of knowledge and skills.

\subsubsection{Suitability}

Adult education centers (Volkshochschule) exist in almost every large city in Germany. Here, education on many different topics is usually offered for several weeks and can be attended for a participation fee. Among these courses, more and more educate digital competences. The caregivers emphasize that these courses do not meet the requirements of people with special needs: "I don't know any offers of adult education centers that would be suitable for our clients, for example" (Caregiver 2, interview, 11 January 2018). Those who cannot read often have no opportunity to participate. They also state that people with intellectual disabilities often need more time and explanations in plain language, which is why more intensive hands-on care is necessary for learning success. However, most adult education centers courses are only offered by one course leader who could then no longer take sufficient care of the needs of all course participants:

However, it is always difficult. Who of the clients can simply attend a course? You have to discuss in advance what is possible for the course constructors and how you could guarantee the supervision for our clients. (Caregiver 1, interview, 10 January 2018)

For most courses, a participation fee is charged and attendees are required to bring their own devices. Since people with disabilities are more likely to experience financial difficulties than people without disabilities (Dobransky \& Hargittai, 2006), the participation fee could constitute a barrier for these people.

\subsubsection{Mobility}

In Germany, the majority of people with intellectual disabilities live in "residential institutions" in which they are cared for 24 hours a day (Dieckmann \& Giovis, 2014). They often have to be accompanied by a caregiver when performing activities of daily living. External courses often cannot be attended because there are not enough employees in the institutions to make such things possible:

But if there is a resident, who is not able to drive to the city center or somewhere else on his or her own I would have to send a staff member along. Very often, this is not possible for me. (Caregiver 3, interview, 12 January 2018)

A further problem seems to be that there are hardly any courses available which offer in-house education. As one caregiver says, there still seems to be a fear of contacting people with disabilities in our society:

The question is always: Who dares to come in here? So I won't get any courses for the clients. We will have to work something out for ourselves. It is sometimes very deterrent to come in here; the past shows us that. So it will be a challenge to find someone for us. (Caregiver 6, interview, 5 May 2018)

Only one caregiver had experiences with "Get Online Week" (Becker et al., 2019), an education program that teaches digital literacy for marginalized groups in Dortmund (a city in Germany). This offer has been described as beneficial: "We are very grateful that our clients will enhance digital literacy through this project 'Get Online Week.' This gives us the opportunity to continue working on the topic and build on it as employees" (Caregiver 2, interview, 11 January 2018).

Due to a perceived lack of services, some institutions come up with their own education programs. They try to familiarize their clients with the Internet. In one facility, a desktop PC is provided for all clients. This is a shared computer that can be used by everyone. However, according to the caregiver surveyed, the PC is not used very often. Indications why the PC is not being used are provided by the surveys of people with intellectual disabilities (see next section), who emphasize that they want to work and learn with up-to-date devices on current topics that interest them. As with the general population, the use of a desktop PC is decreasing, while mobile devices such as smartphones and tablets are becoming increasingly popular (Initiative D21, 2018), even among people with disabilities (Gómez et al., 2017). 


\subsubsection{Lack of Knowledge and Skills}

Caregivers report that not all employees are familiar with digital media and the Internet. Acceptance is not always particularly high: "So I also believe that acceptance is the biggest problem, the technology will only work if it is accepted" (Caregiver 13, interview, 3 July 2018).

Another caregiver reports that employees often reach their limits if they are not familiar with the latest topics. If a client then has a question about Facebook or Snapchat, not every employee is able to deal with those topics: "Thank God a colleague has a Facebook account, so she can take a look at the problem together with the client and solve it sooner than those who have never been at Facebook before" (Caregiver 12, interview, 6 June, 2018). Also, there seemed to be a lack of ideas on how people with disabilities can benefit from digital media and the Internet:

So for the majority of people, the Internet and digital media do not play a role in their everyday lives. But especially because many people have been living here for decades and have their age accordingly. We have an average age of over fifty here. And when they were younger, digitalization was not an issue for them or for us. And so I don't think they are as interested as any other person is at a certain age. (Caregiver 1 , interview, 10 January 2018)

Caregivers doubt that the acceptance of digital topics by their employees, especially older employees, is often not high enough. Recent offers have to meet the needs of people with disabilities. This includes more time to get to know the contents and alternative ways of learning and accessing study material for people who cannot read and write. Furthermore, the lack of independence and mobility of the clients is an important point mentioned by the caregivers. Courses might be designed as an outreach service or in-house offer for the institutions where people with disabilities live or work. To raise acceptance for digital topics in the institutions, employees must be allowed to try out and test the digital media to make their own experiences and to gain understanding of what can be done with digital media and how their clients can benefit from it.

\subsection{Opinions of People with Intellectual Disabilities on Media Education}

After presenting the results of the interviews with the formal caregivers, the spotlight is now on the results from the focus groups featuring people with intellectual disabilities.

\subsubsection{Desire for Social Support}

The frequency of similar statements from the interviews clearly shows that there is a desire for more support con- cerning the usage of digital media by their caregivers: “'’d like to learn how to set up the phone. My friends don't always have time and my brother lives so far away" (Focus group 3, group discussion, 20 February 2018). Another participant states: "Somebody has to show me how to use a smartphone. Then I would be able to do that. Alone!" (Focus group 1, group discussion, 6 February 2018). They mainly wish support for the set-up of their device. Also, when downloading apps from the Appstore and installing them, the participants express uncertainties. This issue is a narrow and sensitive level between being overprotective and provide too little support for questions and concerns of the participants. It is important for the participants that they are taken seriously in their questions and that someone shows them what they can do with the device and how it works.

\subsubsection{Desire for Education Programs}

The focus group discussion also included the question of whether participants had ever attended a training or workshop on digital media or the Internet, or whether they would wish to do so. Here only one participant told that he once took part in a course. Four participants from a social institution told that their institution offers opportunities to use a computer room on certain days of the week. They said that they had tried this once, but that it had been too boring for them: "There's a computer room like this. There you can use the computer. But I didn't know what to do here. It was boring for me" (Focus group 4, group discussion, 14 February 2018).

All other participants said that they had never done anything like this before, but that they would have a great interest in it if the topics were in line with their interests. Here the safe handling of Facebook was mentioned as well as blocking people on WhatsApp or the handling of one's own data on the Internet. Only five participants denied the desire for workshops and offers. They said that they already knew everything that would be of interest to them. When asked whether they knew other functions and possibilities of their device, e.g., navigation with Google Maps, control of their mobile phone via voice control or the reading aloud functionality, the majority of the participants answered with "No." There seemed to be a great interest in these topics, as participants often wanted to know what exactly they could do with those apps or how, for example, they could enter voice commands into their mobile phones. The interest in getting to know such topics seemed to be of high interest for the participants.

The statements of the participants with intellectual disabilities show that there is a great interest in learning and handling digital media, especially concerning the smartphone and the functions and apps. From this, it can be deduced that course formats should in any case deal with such devices. Other devices (e.g., computers or laptops) are considered uninteresting. It can also be seen here that participants seem to feel that their desire to 
learn digital skills is often not taken seriously by their social environment or that there is too little support in the topics relevant to them.

\subsection{Opinions of Experts on Media Education for People with Disabilities}

Finally, the results of the interviews with the experts will be presented. A number of ideas and suggestions were given on how education programs for people with disabilities could be designed.

\subsubsection{Space for Communication and Experimentation}

First of all, it is important to create space for digital topics:

We have seen that spaces have a strong pedagogical effect, a strong supportive pedagogical effect. In pedagogy, the role of space is very important. Space is also a social construct where, for example, repression can prevail, support can prevail. But of course, space also has a physical dimension. (Pelka, interview, 21 August 2019)

Therefore, an organization should provide space for discussion, exchange and especially for digital topics. According to Kaletka, this is not always easy: "We try to find out how such spaces can be defined and created where different people discuss with each other on a normative but also constructive level and express their opinions." (Kaletka, interview, 21 August 2019)

Möser also pointed out that there is a lack of spaces and options that make one's own experiences in organizations, and perhaps also find out that digital participation is beneficial for people with disabilities: "There is a chance to simply try things out" (Möser, interview, 11 September 2019).

To "create space" means that time and opportunities must be given in the institution to talk about digital topics, to express one's opinion and not to be condemned for it. This requires pedagogical and methodological knowledge as well as experiences to create such a space. To "create space" also means that there are physical spaces in which digital devices can be tested. It is important to gain pedagogical support, since the use of a smartphone or tablet needs some explanation for people with intellectual disabilities but also for their caregivers.

\subsubsection{Inclusive Cooperation}

In all of the interviews, the inclusive cooperation between people with and without disabilities was described as a great added value. Working in tandems was mentioned as a concrete example to teach digital literacy but also to learn from each other how to use such devices:
I asked a colleague with a disability if she would like to work in tandem because I saw that she knows a lot about WhatsApp. Well, she can't read, but she has struggled her way through it and learned it without being frustrated. (Zaynel, interview, 6 August 2019)

Zaynel described the added value in the fact that people with disabilities can pass on their own experiences in learning digital skills to other people particularly well. In the development of offers to teach media skills, a tandem between an employee and a client with a disability can offer a wide range of added value: Both sides can learn from each other at eye level to better understand issues, to enable mutual communication and to deal with digital media.

\subsubsection{Up-to-Dateness}

According to the results presented in Section 3.1, social institutions make computers or laptops available for their clients, sometimes without appropriate pedagogical support. Hence, clients with disabilities quickly lose interest or do not even take advantage of these offers.

Bosse posed that orientation towards the interests of the participants can also include using programs like Word or Skype or setting up an email address. Because of these diverse interests and topics, it is essential to ask participants about their interests.

It is also important to ask employees about up-todate topics that have a significant influence on their daily work. This could be topics such as cyberbullying, online shopping or similar. Interestingly, the topics and contents that emerge (e.g., cyberbullying or sexting) are becoming present in social institutions. Möser noted a temporal shift; the topics, which became present in other contexts (e.g., school) already some years ago, also emerge in social organizations:

The fact is that it is becoming more and more present in the social institutions-I like to compare this with the area of school-that those problems with cyberbullying or playing digital games on the smartphone arose in the last years. This significantly influenced the daily work of the employees. (Möser, interview, 11 September 2019)

It becomes clear that the currently emerging topics and problems in social institutions are not entirely new and have already become present in other contexts a few years ago, which is why diverse materials and media concepts already exist in these areas. These can provide a good basis for the adaptation of materials or the development of own media concepts in social institutions (Section 5).

\subsubsection{Flexible Structure}

Flexible workshop structures are very important when teaching digital literacy. This means that there should 
be a plan for the workshop, which should also be as detailed as possible including a timetable, defined topics and goals. It is important not to stick on your plan at every time:

There will be flexible situations and moments to which I have to react. It may take me much longer than I thought, or I might give examples that aren't appreciated at all by the participants. Then I need alternatives, photos or symbols. (Zaynel, interview, 6 August 2019)

In practice, modular structures are particularly suitable. The design featuring modules provides the possibility of shifting the order of the topics according to the interest of the participants. Möser describes his approach with modules as follows:

The first part deals with a few simple but important technical basics. The second module deals with what people use and how they use it. The third module specifically deals with the negative side of digital media, where cyberbullying and sexting are the main topics. Finally, I create a module with secure passwords. (Möser, interview, 11 September 2019)

Bosse also underlines that participants should be allowed to attend the courses voluntarily and selfdetermined and should have the right to reject offers during the course.

\subsubsection{Create Relationships!}

Relationships and trust between course instructors, the participants and their assistants should be built up as an important and not to be underestimated success component. Zaynel also describes the following situation:

We usually ask the participants at the beginning what they would like to do in the course. Many don't even think about what they want to do with their smartphones. (Zaynel, interview, 6 August 2019)

It can be a possibility to first meet the participants, to make a short social gathering, in which it is not primarily about the topics of the workshop, but about the hobbies and ideas of the participants. Bosse described, for example:

We had gone over to make a social gathering before the course started. It was not really about computer usage. So we already introduced the course once, but we also had coffee and cake. (Bosse interview, August 20, 2019)

A more informal situation makes it possible to get to know each other, which can represent a good basis for the development of the workshop topics. Even if the gen- eral conditions do not allow for a longer period, a short phase should include this at the beginning of the course.

\subsubsection{Mission Statements of the Institution}

Social institutions respond very differently to the digitization of their facilities. Institutions should decide for themselves whether they want to stand up for the promotion of media literacy of their clients and should be aware of what that means in everyday life:

Then you have to ask yourself as an institution if you are willing to go along with it [digital media] in everyday life. Institutions must be aware that clients can be frustrated and fail. They need to be aware that topics such as abuse can logically be difficult to address. This also happens in the context of school and youth work. (Möser, interview, 11 September 2019)

The team of the institution needs to find a common positive position toward digitization. A concrete approach could be to develop a mission statement on these issues in a working group or to expand the mission statement in line with digital topics. The employees of the institutions must be involved in this process. Without the acceptance of the employees, such a step is often ineffective (see next section). This can build a suitable base for accompanying the clients pedagogically in the use of their devices in everyday life.

\subsubsection{Acceptance among Employees}

Pelka described the employees in the facilities as an "important set screw" and highlights an issue as follows:

Many people working in education, social and care support perceive technology as contrariwise to their work. There is a professional ethic that is closely linked to nearness to people, perhaps physical and emotional. Technologies are often regarded as a hindrance there. (Pelka, interview, 21 August 2019)

According to Pelka, employees in these areas need to understand that technologies can help achieve clients' goals. According to Kaletka, it is also essential that employees should be aware of the importance of digital literacy for people with disabilities as a great and central aspect of participation.

Möser also notes that "awareness of the topic's relevance to the target group is lacking" and "a huge amount of will and need to deal with these issues" (Möser, interview, 11 September 2019).

First of all, it is important to catch up with employees' opinions and take them seriously. Secondly, the employees must be sensitized to their important role in the process of competence and media education. Thirdly, there is a need to be qualified in their own competences by training and further education. 


\subsubsection{Course Design for People with Disabilities}

Course formats for people with intellectual disabilities should be based on general educational principles. Möser made the experience that the participants of the courses understand the content very well and emphasizes that it is important to avoid the following considerations: "What content should be left out" or "what are the participants capable of doing?" (Möser, interview, 11 September 2019).

Zaynel emphasizes that the concept of a Universal Design is a good basis for designing inclusive course formats:

I'm a big fan of Universal Design. So that you use what all people use. I don't use any special systems in the courses as I don't find them so profitable. If I orientate myself on general programs and systems [e.g., smartphones and tablets] the chance of acceptance is greater. (Zaynel, interview, 6 August 2019)

The concept of Universal Design can also be extended to the design of education programs and materials, and is known in this context as Universal Design for Learning (UDL): "The essence of UDL is flexibility and the inclusion of alternatives to adapt to a myriad variations in learner needs, styles, and preferences" (Rose, 2000). Bosse reported having positive experiences with pictures or pictograms as support for communication and course content. The use of such pictures and pictograms, as well as alternative learning formats and learning materials, are a good basis to adapt the learning content to the needs of the participants.

\subsubsection{Information and Cooperation}

Some of the institutions have little knowledge about offers in their environment (Section 3.1.2, e.g., PIKSL Laboratory, TMT Bildungsprojekte, "Get Online Week"). More public relation must be carried out. Furthermore, it is important that the institutions actively seek information. The establishment of a staff unit or a coordinator in the social organizations could be a way of performing these tasks. The tasks of such a person could include identification of funding opportunities for the acquisition of technical infrastructure.

Today, some offers to promote digital literacy of people with disabilities are available in Germany, but remain still very rare and, above all, only in some regions of the country. Möser told that it as important to network with partners from science and practice to advance the topic further. A coordinating person or a speaker could fulfill such a function in a social organization very well, as already described.

For being "not a drop in the ocean" (Möser, interview, 11 September 2019), education programs should not only be offered when the situation is already escalating, but on a long-term basis. According to Bosse, it would be optimal if workshop topics could be implemented immediately afterward in larger media projects.

\section{Discussion}

This study examined different stakeholder perspectives towards the design of education programs for people with disabilities. The following interesting results can be noted:

- Formal caregivers were of the opinion that existing course formats are neither designed to meet the requirements of people with intellectual disabilities (e.g., easy language, number of instructors) nor those of social institutions (e.g., personal resources, time concerns). Because formal caregivers are afraid that nobody dares to come into the institutions to train people with disabilities (e.g., fear of contact), only three institutions try to do their own small ICT training sessions with their clients to introduce them to digital topics. However, these are not attended by people with intellectual disabilities. This leads to the second important finding of this study.

- Participants with intellectual disabilities reported that they often lack support when they use or access the Internet or digital media. Thus, their questions are often not answered. If offers exist in their living institutions, they describe them as boring because they do not deal with their devices (i.e., smartphones) or preferred topics (i.e., Facebook, Instagram or WhatsApp). The lack of interest towards existing education offers by people with intellectual disabilities was equated with a general lack of interest by formal caregivers in enhancing digital literacy for this group of people. Contrary, this study illustrated that the participants with intellectual disabilities showed a great interest in enhancing their digital literacy but criticized that previous offers in their living institutions often do not meet their interests.

Here it can be noted that such misunderstandings arise because people with intellectual disabilities seem not to be asked for their opinion or interests. Recent studies found that, in contrast to other types of disability, people with intellectual disabilities in particular are significantly more likely to experience paternalism (McConkey \& Smyth, 2003), stigmatization (Chadwick et al., 2013) and underestimations of competencies and skills (Chiner et al., 2017). As a consequence, the perception of rights, and the striving for life goals is often significantly reduced (Corrigan \& Rao, 2012). Due to these attributed prejudices, people with intellectual disabilities are often ignored or not asked for their opinion. In this study, it was shown that this is also true for using and accessing the Internet. As a consequence, misunderstandings between formal caregivers and the perceptions of people with in- 
tellectual disabilities exist towards the design, content and conduction of education programs.

Furthermore, it must also be noted that the misunderstandings are not only one-sided. Formal caregivers are often not given the opportunity to inform themselves about new technologies or education programs for their clients. Temporal, personal and motivational reasons are mentioned as barriers by formal caregivers in the studied setting. As already mentioned, it requires "financial and time resources, cognitive skills or the recognition that digital processes are important" (Pelka, 2017). The fact that these resources are often lacking in social institutions has already been demonstrated by Ramsten et al. (2017). Interestingly, this study shows that formal caregivers and people with intellectual disabilities mentioned a desire for more support to be able to familiarize with new technologies. However, only three of the 24 caregivers in this sample saw a need for action and created their own short ICT interventions. Thus, the majority of caregivers did not (yet) consider the topic as relevant to take action.

A multi-layered problem is emerging here. First of all, Internet usage and enhancing digital literacy is perceived as an issue that does not yet requires action. On the one hand, there is the problem that some caregivers design ICT interventions for their clients, which are not used by people with intellectual disabilities. On the other hand, formal caregivers themselves often lack digital literacy, as well as didactic and conceptual pedagogical skills to effectively design such education programs. The question of how to meet these different requirements is the central question of this article. To answer it, two perspectives can be adopted: a formal, designing perspective and a content perspective. In this study, the interviewed experts gave some hints on the design of education programs, which were already presented in Section 3.3. In the following, the mentioned aspects are summarized and can serve as a guideline for the design of education programs:

1. Create space for an open exchange on attitudes and topics related to digitization. Provide opportunities to gain personal experience;

2. Reflect on institutional ideals and discuss the place the digitization should take in the facility. Improve the mission statement;

3. Ask employees for their opinion and take fears and wishes seriously to raise acceptance;

4. Inform yourself about digital topics to establish possible cooperation;

5. Work within inclusive groups or tandems on specific topics;

6. Use UDL to derive practical operation criteria for inclusive education programs;

7. Take into account the topics and wishes of the participants;

8. Orientate on modular structures in terms of topic, content and organization;
9. Build relationships to understand the participant's and individual needs;

10. Treat people with disabilities like everyone else.

The points mentioned above can be arranged on the axes of Figure 1 and help to further define the needs, goals and methods of such education programs.

One way to address the complex problem found in this study is to analyze experiences of participants, levels of media literacy and the quality of an education program. Figure 1 can serve as orientation for the persons who design such offers, but it can also be useful for social institutions to find or design the appropriate offer for their institution.

The left side of the figure (y-axis) shows five different levels of service quality described by Pelka (2017). Providing access to the Internet in a social institution might be the first and lowest level of service quality. When formal caregivers and people with intellectual disabilities interact with each other and develop solutions for current topics (e.g., cyber mobbing), this would lead to a higher level of quality. The middle axis shows three contents of media literacy according to Baacke (1999). Here, the aim should be to find out about the current status quo of media literacy, attitudes and needs of course participants and to estimate at what level(s) the education program should take place. For this purpose, it would be useful to conduct a media analysis of potential participants before starting such course. The Personas concept can offer such a possibility (Maier \& Thalmann, 2010). The $x$-axis describes the degree of experience (from limited to numerous). Experiences are one of the most important factors for technology acceptance (Venkatesh \& Bala, 2008). Heitplatz et al. (2019) recently described how the experiences of formal caregivers in the use of technology can have a positive or negative impact on the use of people with intellectual disabilities. Thus, the evaluation of past experiences should play an important role in the creation of education programs.

Many of the points mentioned by the expert as well as the results of formal caregivers and people with intellectual disabilities can be analyzed on the basis of these three axes. Starting with the experiences ( $x$-axis), the sample of this study shows that formal caregivers often reach their limits when they have to use technologies (see Section 3.1.3) and therefore the experiences can be estimated between a limited and moderate level. It seems to be similar for interviewed people with intellectual disabilities, as they stated that they have a strong interest in acquiring more competencies (see Section 3.2.2). Thus, an education program for people in this sample could aim to expand the use, i.e., the first level of media literacy, to create acceptance (see Section 3.3.7), and to obtain information about new developments and technologies. Since people with intellectual disabilities and formal caregivers in this study expressed similar wishes, an inclusive education program for both groups of people could be designed. Such an in- 


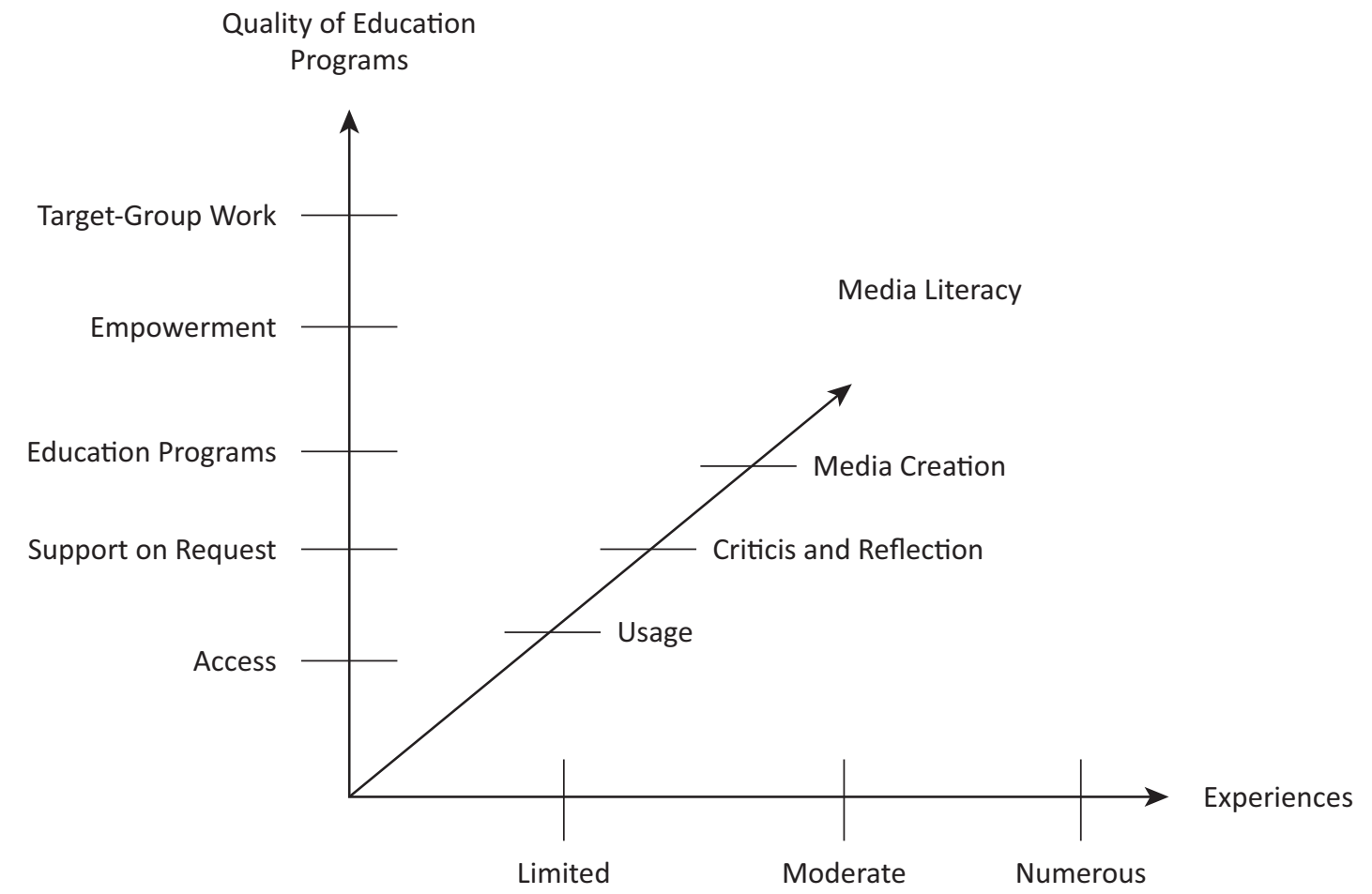

Figure 1. Three levels of analysis for the design of education programs.

clusive cooperation (e.g., working in tandems), as Zaynel (interview, 6 August 2019) stated, provides a high level of quality. Here it is important to take pedagogical and didactic methods into account. A flexible workshop structure with different modules, as described by Möser, or using the UDL as a basic method for designing the content should be considered to meet the different learning needs of the participants.

With the three levels of analysis presented here, the four guiding questions and the advice of the experts, it is possible to develop education programs for very different groups of people or to analyze needs in the institution or company. This analysis does not only consider the formal design of workshops but also encourages reflection on the pedagogical methods, the needs of the participants and the quality of education programs. Hence, designing education programs is not about making special courses for people with disabilities. Rather, it is taking general educational principles and adapting them at one point or another to the intellectual level of the participants. Depending on the group of people and requirements, specific and needs-oriented materials and didactic methods can then be used to implement the education program.

\section{Conclusion}

People with intellectual disabilities are one of many groups of persons in our society who are often affected by digital divides, face disadvantages in social life (e.g., less social contacts, lower socio-economic status) and have to deal with stigmatizations. Currently, technical aids and smartphone applications have become available for people with hearing or visual impairments (see Section 1). People with intellectual disabilities have so far not been taken into account in research and development of technical solutions. Furthermore, people with intellectual disabilities are often regarded as vulnerable and incompetent and are ignored in their opinions which are also results in this study. Therefore, it is important that this group of people has opportunities to improve their digital literacy to participate in the Internet and to exercise their rights to a self-determined access and usage.

This study indicates that clients of institutions often already use digital media. The decision as to whether or not a social institution wishes to address the issue of digitalization has already been made. Unfortunately, people with intellectual disabilities but also their formal caregivers often lack support and opportunities to enhance their digital literacy. The focus group study showed the willingness of people with intellectual disabilities to learn about the topic. The interviews with the formal caregivers' illustrated a lack of awareness that digital topics are becoming more and more important for people with intellectual disabilities. All the institutions surveyed lack a structured and overarching media concept. As discussed in Section 5, these are criteria for designing workshops (e.g., flexible structure, social gathering) and organizational criteria as precondition for having such education offers. In Germany, awareness of such issues in social work and in working with people with disabilities has only just begun to rise. The topic needs to be developed over the next years. This article provides some first ideas for the design of education programs for peo- 
ple with disabilities. The guideline is designed to better understand and address the needs of institutions, caregivers and people with disabilities in the implementation of education programs.

\section{Acknowledgments}

I acknowledge financial support from the Deutsche Forschungsgemeinschaft and TU Dortmund within the funding program Open Access Publishing.

\section{Conflict of Interests}

The author declares no conflict of interests.

\section{References}

Ågren, K. A., Kjellberg, A., \& Hemmingson, H. (2019). Digital participation? Internet use among adolescents with and without intellectual disabilities: A comparative study. New Media \& Society. Advance online publication. https://doi.org/10.1177/ 1461444819888398

Baacke, D. (1999). "Medienkompetenz": Theoretisch erschließend und praktisch folgenreich [Media literacy: theoretical and practical consequences]. Medien+Erziehung, 43(1), 7-12.

Bawden, D. (2008). Origins and concepts of digital literacy. In C. Lankshear \& M. Knobel (Eds.), Digital literacies: Concepts, politics and practices (pp. 17-32). New York, NY: Peter Lang.

Becker, M., Benner, A., Borg, K., Hüls, J., Koch, M., Kost, K., ... Pelka, B. (2019). How to design an intervention to raise digital competences: ALL DIGITAL WeekDortmund 2018. In M. Antona \& C. Stephanidis (Eds.), Proceedings of universal access in human-computer interaction: Theory, methods and tools (pp. 389-407). Basel: Springer.

Bosse, I., \& Pola, A. (2017). Applying film and multimedia to the inclusive teaching and learning in Germany: Problems and solutions. In M. Antona \& C. Stephanidis (Eds.), Universal access in human-computer interaction access to learning, health and well-being (pp. 129-142). Cham: Springer.

Bühler, C., \& Pelka, B. (2014). Empowerment by digital media of people with disabilities. Three dimensions of support. In K. Miesenberger, D. Fels, D. Archambault, P. Penanz, \& W. Zagler (Ed.), Proceedings of computers helping people with special needs (pp. 17-24). Cham: Springer.

Chadwick, D. D., Quinn, S., \& Fullwood, C. (2017). Perceptions of the risks and benefits of Internet access and use by people with intellectual disabilities. British Journal of Learning Disabilities, 45(1), 21-31.

Chadwick, D., Wesson, C., \& Fullwood, C. (2013). Internet access by people with intellectual disabilities: Inequalities and opportunities. Future Internet, 5, 376-397.
Chiner, E., Gómez-Puerta, M., \& Cardona-Moltó, M. C. (2017). Internet use, risks and online behavior: The view of Internet users with intellectual disabilities and their caregivers. British Journal of Learning, Disabilities, 45(3), 190-197.

Corrigan, P. W., \& Rao, D. (2012). On the self-stigma of mental illness: Stages, disclosure, and strategies for change. Canadian Journal of Psychiatry, 57(8), 464-469.

des Power, M. R., Power, R., \& Rehling, B. (2007). German deaf people using text communication on JSTOR. American Annals of the Deaf, 152(3), 291-301.

Dieckmann, F., \& Giovis, C. (2014). Demographic changes in the older adult population of persons with intellectual disability in Germany. Journal of Policy and Practice in Intellectual Disabilities, 11(3), 223-234.

Dobransky, K., \& Hargittai, E. (2006). The disability divide in internet access and use. Information Communication and Society, 9(3), 313-334.

Dobransky, K., \& Hargittai, E. (2016). Unrealized potential: Exploring the digital disability divide. Poetics, 58, 18-28.

Gómez, J. C., Torrado, J. C., \& Montoro, G. (2017). Using smartphones to assist people with down syndrome in their labour training and integration: A case study. Wireless Communications and Mobile Computing. Advance online publication. https://doi.org/ 10.1155/2017/5062371

Haage, A., \& Bosse, I. K. (2017). Media use of persons with disabilities. In M. Antona \& C. Stephanidis (Eds.), Universal access in human-computer interaction. Human and technological environments (pp. 419-435). Basel: Springer.

Heitplatz, V. N., Bühler, C., \& Hastall, M. R. (2019). Caregiver's influence on smartphone usage of people with cognitive disabilities: An explorative case study in Germany. In M. Antona \& C. Stephanidis (Eds.), Universal access in human-computer interaction. Multimodality and assistive environments (pp. 98-115). Basel: Springer.

Hoppestad, B. S. (2013). Current perspective regarding adults with intellectual and developmental disabilities accessing computer technology: Disability and rehabilitation. Assistive Technology, 8(3), 190-194.

Initiative D21. (2018). D21 digital index 2018/2019 Jährliches Lagebild zur Digitalen Gesellschaft [D21 digital index 2018/2019 annual review of the digital society]. Lampertswalde: Stoba Druck GmbH.

Ismaili, J., \& Ibrahimi, E. H. O. (2017). Mobile learning as alternative to assistive technology devices for special needs students. Education and Information Technologies, 22(3), 883-899.

Keates, S. (2019). Universal access: The challenges ahead. In M. Antona \& C. Stephanidis (Eds.), Proceedings of universal access in human-computer interaction: Theory, methods and tools (pp. 100-112). Basel: Springer.

Koltay, T. (2011). The media and the literacies: Media lit- 
eracy, information literacy, digital literacy. Media Culture Society, 33(2), 211-221.

Lee, W-J., \& Shin, S. (2017). Effects of product smartness on satisfaction: Focused on the perceived characteristic of smartphones. Journal of Theoretical and Applied Electronic Commerce Research, 13(2), 1-14.

Li-Tsang, C. W. P., Yeung, S. S. S., Choi, J. C. Y., Chan, C. C. H., \& Lam, C. C. S. (2007). The effect of systematic information and communication technology (ICT) Training programme for people with intellectual disabilities. The British Journal of Developmental Disabilities, 52(1), 3-18.

Löfgren-Mårtenson, L., Molin, M., \& Sorbring, S. (2018). $\mathrm{H} @$ ssles and hopes on the Internet: What professionals have encountered in dealing with Internet use and sexuality among youths with intellectual disabilities. Papers of Social Pedagogy, 8(1), 66-82.

Maier, R., \& Thalmann, S. (2010). Using personas for designing knowledge and learning services: Results of an ethnographically informed study. International Journal of Technology Enhanced Learning, 2(1), 58-74.

McConkey, R., \& Smyth, M. (2003). Parental perceptions of risks with older teenagers who have severe learning difficulties contrasted with the young people's views and experiences. Child \& Society, 17(1), 18-31.

Murata, M. (2019). Smartphone-based localization for blind navigation in building-scale environments. Pervasive and Mobile Computing, 57, 14-32.

Nälsund, R., \& Gardelli, Å. (2012). 'I know, I can, I will try': Youths and adults with intellectual disabilities in
Sweden using information and communication technology in their everyday life. Disability and Society, 28(1), 28-40.

Pelka, B. (2017). Digitale Teilhabe: Aufgaben der Verbände und Einrichtungen der Wohlfahrtspflege [Digital participation. Tasks of public welfare]. In $\mathrm{H}$. Kreidenweis (Ed.), Digitaler Wandel in der Sozialwirtschaft [Digital change in social economy] (pp. 57-78). Baden-Baden: Nomos.

Ramsten, C., Marmstål Hammar, L., Martin, L., \& Göransson, K. (2017). ICT and intellectual disability: A survey of organizational support at the municipal level in Sweden. Journal of Applied Research in Intellectual Disabilities, 30, 705-713.

Rose, D. (2000). Walking the walk: Universal design on the web. Journal of Special Education Technology, 15(3), 45-49.

Shpigelman, C.-N. (2018). Leveraging social capital of individuals with intellectual disabilities through participation on Facebook. Journal of Applied Research in Intellectual Disabilities, 31(1), 79-91.

Venkatesh, V., \& Bala, H. (2008). Technology acceptance model 3 and a research agenda on interventions. Decision Science, 39(2), 273-315.

Zorn, I., Schluchter, J.-R., \& Bosse, I. (2019). Theoretische Grundlagen inklusiver Medienbildung [Theory of inclusive media education]. In I. Bosse, J.-R. Schluchter, \& I. Zorn (Eds.), Handbuch Inklusion und Medienbildung [Manual on inclusion and media education] (pp. 16-33). Weinheim: Beltz Juventa.

\section{About the Author}

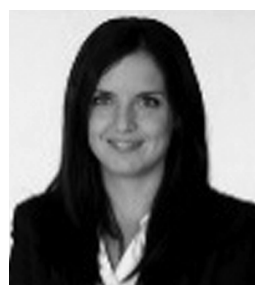

Vanessa Heitplatz is a PhD Candidate at TU Dortmund, Germany. Her research focus is on the usage of digital media-especially smartphones-by people with intellectual disabilities. In her doctoral thesis, she investigates opinions of facility managers, formal caregivers, and people with intellectual disabilities within a mixed-methods research design. The research design includes semi-structured interviews with facility managers of social institutions, questionnaires with staff members in those institutions and focus groups with people with intellectual disabilities. 